\title{
Deficiency of inducible and endothelial nitric oxide synthase results in diminished bone formation and delayed union and nonunion development
}

Citation for published version (APA):

Meesters, D. M., Neubert, S., Wijnands, K. A. P., Heyer, F., Zeiter, S., Ito, K., Brink, P. R. G., \& Poeze, M. (2016). Deficiency of inducible and endothelial nitric oxide synthase results in diminished bone formation and delayed union and nonunion development. Bone, 83, 111-118. https://doi.org/10.1016/j.bone.2015.11.006

DOI:

10.1016/j.bone.2015.11.006

Document status and date:

Published: 01/01/2016

Document Version:

Accepted manuscript including changes made at the peer-review stage

Please check the document version of this publication:

- A submitted manuscript is the version of the article upon submission and before peer-review. There can be important differences between the submitted version and the official published version of record. People interested in the research are advised to contact the author for the final version of the publication, or visit the DOI to the publisher's website.

- The final author version and the galley proof are versions of the publication after peer review.

- The final published version features the final layout of the paper including the volume, issue and page numbers.

Link to publication

\footnotetext{
General rights

- You may freely distribute the URL identifying the publication in the public portal. follow below link for the End User Agreement:

www.tue.nl/taverne

Take down policy

If you believe that this document breaches copyright please contact us at:

openaccess@tue.nl

providing details and we will investigate your claim.
}

Copyright and moral rights for the publications made accessible in the public portal are retained by the authors and/or other copyright owners and it is a condition of accessing publications that users recognise and abide by the legal requirements associated with these rights.

- Users may download and print one copy of any publication from the public portal for the purpose of private study or research.

- You may not further distribute the material or use it for any profit-making activity or commercial gain

If the publication is distributed under the terms of Article $25 \mathrm{fa}$ of the Dutch Copyright Act, indicated by the "Taverne" license above, please 


\section{DEFICIENCY OF INDUCIBLE AND ENDOTHELIAL NITRIC OXIDE SYNTHASE RESULTS IN DIMINISHED BONE FORMATION AND DELAYED UNION AND NONUNION DEVELOPMENT}

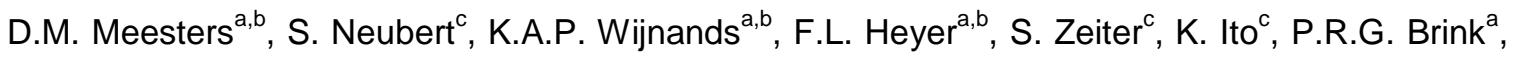
M. Poeze $e^{a, b}$

a Department of Surgery and Trauma surgery, Maastricht University Medical Center, PO Box 5800, 6202 AZ, Maastricht, The Netherlands

${ }^{\mathrm{b}}$ NUTRIM School for Nutrition and Translational Research in Metabolism, PO Box 616, 6200 MD, Maastricht, The Netherlands

${ }^{c}$ AO Research Institute Davos, Clavadelerstrasse 8, 7270, Davos, Switzerland.

\section{Corresponding author:}

Dennis M. Meesters

Department of Surgery and Trauma surgery, Maastricht University Medical Center PO Box 5800

6202 AZ Maastricht, The Netherlands

Phone $+31(0) 433881494$

d.meesters@maastrichtuniversity.nl

Keywords: nonunion, delayed union, nitric oxide, arginine, fracture healing 


\section{ABSTRACT}

Background: Between $5 \%$ and $10 \%$ of all fractures fail to heal adequately resulting in nonunion of the fracture fragments. This can significantly decrease a patient's quality of life and create associated psychosocial and socio-economic problems.

Nitric oxide (NO) and nitric oxide synthases (NOS) have been found to be involved in fracture healing, but until now it is not known if disturbances in these mechanisms play a role in nonunion and delayed union development. In this study, we explored the role of endothelial and inducible NOS deficiency in a delayed union model in mice.

Materials and methods: A $0.45 \mathrm{~mm}$ femur osteotomy with periosteal cauterization followed by plate-screw osteosynthesis was performed in the left leg of 20-24 week old wild type, $\mathrm{Nos2}^{/-}$and Nos $^{-/}$mice. Contralateral unfractured legs were used as a control. Callus volume was measured using micro-computed tomography $(\mu \mathrm{CT})$ after 28 and 42 days of fracture healing. Immuno histochemical myeloperoxidase (MPO) staining was performed on paraffin embedded sections to assess neutrophil influx in callus tissue and surrounding proximal and distal marrow cavities of the femur. After 7 and 28 days of fracture healing, femurs were collected for amino acid and RNA analysis to study arginine-NO metabolism.

Results: With $\mu \mathrm{CT}$, delayed union was observed in wild type animals, whereas in both $\mathrm{Nos2}^{-/}$and $\operatorname{Nos}^{-/}$mice nonunion development was evident. Both knock-out strains also showed a significantly increased influx of MPO when compared with wild type mice. Concentrations of amino acids and expression of enzymes related to the arginine-NO metabolism were aberrant in NOS deficient mice when compared to contralateral control femurs and wild type samples.

Discussion and conclusion: In the present study we show for the first time that the absence of nitric oxide synthases results in a disturbed arginine-NO metabolism and inadequate fracture healing with the transition of delayed union into a nonunion in mice after a femur osteotomy. Based on these data we suggest that the arginine-NO metabolism may play a role in the prevention of delayed unions and nonunions. 


\section{INTRODUCTION}

Normal fracture healing is a process of partially overlapping phases of inflammation, callus formation and bone remodeling in which there is an interplay between various cells, growth factors and extracellular matrix[1]. However, five to ten percent of all patients experience difficulties during the healing process[2] resulting in delayed union or nonunion of the fracture, indicated by persisting fracture lines and presence of a hypertrophic or atrophic callus[3]. Malnutrition, drug therapy, inadequate stabilization of the fracture and/or inadequate blood supply (i.e. periosteal injury) contribute to nonunion development[4, 5].

Adequate production of NO (nitric oxide), a free radical produced during the conversion of arginine into citrulline by nitric oxide synthases (NOSs) stimulates bone cells to regulate bone remodeling and influences vascular reactivity[6-8]. Furthermore, NO is suggested to stimulate polyamine production through the formation of ornithine, as precursors of collagen synthesis $[9$, 10]. An intricate interplay exists between the substrate availability of arginine and citrulline and the NOS enzyme complex (Figure 1). Disturbances in arginine and citrulline have already been associated with an impaired fracture healing resulting in nonunion in humans[11]. However, the pathogenesis has not been elicited yet.

In vivo studies in rats showed the presence and localization of NOS isoforms in callus samples after creation of a femoral fracture. mRNA and protein activity of inducible NOS (iNOS or NOS2) was present during the first phase of fracture repair and was mainly localized within the intramembranous region along the edge of the periosteal callus. The constitutive and calcium dependent endothelial (eNOS or NOS3) and neuronal NOS (nNOS or NOS1) were found in later stages of fracture healing and mainly in cells lining blood vessels and in the fibrochondral region between fibrous tissue and cartilage respectively[12-14].

We hypothesized that low amounts of NO and disturbances in arginine substrate metabolism due to an absence of either the Nos2 or Nos3 gene will inhibit callus formation and increase the risk of nonunion. Therefore, we studied the formation of callus and the arginine metabolism after a femur osteotomy with periosteal cauterization in a mouse model of delayed union. 


\section{MATERIALS AND METHODS}

\subsection{Animals and surgical procedure}

In this study, skeletally mature, 20 to 24 week old specific pathogen free (SPF), female C57BI6/J (RCC Switzerland) and $\mathrm{Nos}^{-/}$and $\mathrm{Nos}^{-/}$, both backcrossed more than 10 generation into the C57BI6/J background, with constructs previously described by Laubach et a[15] and Shesely et a[16] respectively (kindly provided by Dr. Theo Hakvoort, University of Amsterdam, The Netherlands), mice were used. All mice were housed in groups of five in individually ventilated cages (IVC) with a 12-hour day-night cycle. Mice were fed standard diet (3436, Prowimi, Switzerland) and water ad libitum. All animals were allowed to acclimatize for 2 weeks prior to surgical intervention. After these 2 weeks, mice were randomly assigned to the micro-computed tomography ( $\mathrm{N}=9$ /group), the amino acid and RNA analysis ( $\mathrm{N}=6 /$ group) or the histology ( $\mathrm{N}=9$ /group) groups for analysis. See table 1 for a complete overview of animals per mouse strain, group of analysis and days of follow-up.

Anaesthesia was induced by placing the mice in an induction box flooded with isoflurane (Isoflurane, Baxter AG, Switzerland). For intraoperative analgesia, $0.1 \mathrm{mg} / \mathrm{kg}$ s.c. buprenorphine (Temgesic, Essex Chemie AG, Switzerland) was administered. During surgery, animals were kept under $1.5-2 \%$ isoflurane inhalation anaesthesia and on a heating pad to prevent hypothermia. After aseptic preparation of the surgical field, animals were placed in prone position and a lateral skin incision starting at the base of the tail towards the left knee was made. By blunt dissection between the quadriceps and biceps femoris muscles, the femur was exposed and a 1 $\mathrm{mm}$ segment of periosteum was cauterized circumferentially during 0.5 seconds. The soft tissue was protected by a Teflon foil during cauterization. Thereafter, an internal plate[17] $(7 \times 1.5 \times 0.7$ mm, MouseFix, RISystems Davos, Switzerland) was placed on the femur and after predrilling with a $0.33 \mathrm{~mm}$ drill bit the plate was fixed with four angular stable MouseFix screws $(2.0 \mathrm{~mm}$ in length). Following fixation, a $0.45 \mathrm{~mm}$ mid-diaphyseal femoral gap osteotomy was performed with a Gigli wire saw in the center of the cauterized segment. Each screw was untightened by half a turn to induce secondary fracture healing[18]. Fascia and skin were closed in routine fashion (5-0 
Vicryl Rapide, Ethicon and Proline, Ethicon, Belgium). At the end of surgery, plate placement and fixation was confirmed radiographically. In the following 48 hours, mice received $0.1 \mathrm{mg} / \mathrm{kg}$ s.c. buprenorphine every $10-14$ hours and for the first 5 days postoperatively $8 \mathrm{mg}$ paracetamol per os/mouse/day was given through the drinking water (Dafalgan, Upsamedica, Switzerland).

Mice were sacrificed using $\mathrm{CO}_{2}$ following different periods of fracture healing ( 7,28 and 42 days after osteotomy). The veterinary welfare and ethics committee of the Canton of Graubünden (Switzerland) approved the experimental set-up and procedures of this study (permit number GR 23/2006).

\subsection{Amino acid measurements}

To determine arginine, citrulline and ornithine concentrations, blood was collected post mortem in heparinized tubes on ice for amino acid measurements and centrifuged immediately ( $4 \stackrel{\circ}{\circ}, 15$ min at $8,500 \mathrm{~g}$ ) to obtain plasma. For amino acid analysis, plasma was deproteinized using acetonitrile (ratio plasma : acetonitrile $1: 2$ ), vortexed and stored until further analysis at $-80 \stackrel{\circ}{\circ}$. Tissue samples for amino acid measurements were snap frozen in liquid nitrogen directly after harvesting. Before analysis, frozen homogenized tissue samples were added to $0.1 \mathrm{~g}$ of glass beads $(1.0 \mathrm{~mm}$ diameter) in $250 \mu \mathrm{l}$ of $5 \%$ sulfosalicylic acid for deproteinization, beaten for 30 seconds at maximum speed with mini-beadbeater (BioSpec Products, Bartlesville, Oklahoma, USA) and stored at $-80^{\circ} \mathrm{C}$ until further analysis. The contralateral right femurs of the mice were used as unfractured control bones. Plasma and tissue amino acid concentrations were measured by HPLC as previously described[19].

The arginine availability in plasma and callus tissue was calculated as [arginine] / ([ornithine] + [lysine]). This is based on the uptake of arginine, ornithine and lysine in cells via the $\mathrm{y}^{+}$transport system[20, 21].

\subsection{Immuno histochemistry}

Following euthanasia, internal fixators were removed from the femurs and samples were fixed in 4\% buffered paraformaldehyde solution and decalcified using EDTA. Samples were embedded in 
paraffin and $4 \mu \mathrm{m}$ sections were prepared. For immuno histochemical analysis, sections were deparafinised in xylene and rehydrated from graded ethanol to water. Endogenous peroxidase activity was blocked using $0.3 \%$ hydrogen peroxide in methanol (15 min). Sections were incubated for 1 hour with a MPO (myeloperoxidase) primary antibody (polyclonal antibody, A0398, DakoCytomation, Glostrup, Denmark) at room temperature. Specific antibody-binding was detected with a horseradish peroxidase (HRP) labeled goat-a-rabbit IgG antibody (Jackson Immunoresearch, Westgrove, PA, USA). Visualization of the staining was performed with 3amino-9-ethylcarbazole (AEC) and followed by nuclear counter staining with haematoxylin (Sigma, St. Louis, MO, USA). Scoring of MPO was done on 3 separate locations on the section (proximal part, distal part and callus) by two independent, blinded, researchers and on a three point scale (0: no MPO detectable, 1: intermediate signal and 2: strong signal).

\section{$2.4 \quad$ Histology}

$4 \mu \mathrm{m}$ sections were used after fixation and decalcification as described above. Sections were deparafinised in xylene and rehydrated from graded ethanol (100\%-96\%-70\%) to distilled water. For morphogenetic analysis, sections were stained in hematoxylin and eosin (H\&E).

\section{$2.5 \quad$ RNA isolation and qPCR}

After collecting samples, tissues were snap frozen in liquid nitrogen and stored at $-80{ }^{\circ} \mathrm{C}$ until further analysis. Before RNA isolation, samples were crushed with pestle and mortar on liquid nitrogen. To isolate total RNA, crushed samples were incubated in Trizol and were beaten with glass beads thrice for $10 \mathrm{~s}$ with a mini-beadbeater (Biospec Products, Bartlesville, OK, USA). Afterwards, RNA was precipitated using isopropanol and centrifugation (30 min, 11,000 rpm, 4 ${ }^{\circ}$ C). After precipitation, pellets were washed with $80 \%$ ethanol and air dried before dissolving in DEPC (diethylpyrocarbonate) treated water. Genomic DNA was removed using DNase I treatment (Promega, Madison, WI, USA). RNA was precipitated using 100\% ethanol with $3 \mathrm{M}$ $\mathrm{NaAc}$ for 30 minutes at $-80{ }^{\circ} \mathrm{C}$ before centrifugation (30 min, 11,000 rpm, $4 \stackrel{\circ}{\circ} \mathrm{C}$ ). After washing 
with $80 \%$ ethanol, pellets were dissolved in $20 \mu$ DEPC treated water. Standard cDNA synthesis was performed by using the iScript cDNA synthesis kit (Biorad Products, Hercules, CA, USA).

For quantitative PCR, iQ SYBR Green Supermix (Biorad Products, Hercules, CA, USA) and gene-specific Nos2, Nos3, Arg1, ActB and Ppia forward and reversed primers (see table 2) were added to the cDNA. The cDNA was amplified using the MyiQ system (Biorad Products, Hercules, CA, USA) via a 3-step program: 40 cycles of denaturation (95 $\left.{ }^{\circ} \mathrm{C}, 10 \mathrm{~s}\right)$, annealing (60 $\left.{ }^{\circ} \mathrm{C}, 20 \mathrm{~s}\right)$ and elongation (70 $\left.{ }^{\circ} \mathrm{C}, 20 \mathrm{~s}\right)$. Further analysis was performed using the MyiQ software (Biorad Products, Hercules, CA, USA).

\section{$2.6 \quad$ Radiologic analysis}

Femurs were scanned by micro-computed tomography ( $\mu \mathrm{CT} 40$, Scanco Medical, Switzerland) at $70 \mathrm{kV}_{\mathrm{p}}$ and $114 \mu \mathrm{A}$ with $200 \mathrm{~ms}$ integration time. The femur was positioned, so that its longitudinal axis was oriented perpendicular to the X-ray radiation. This position was maintained during the analysis by inserting a pin in the most proximal and distal screw hole, which fixed the bone. The volume between the two screw holes was measured with 400 two-dimensional transversal cross-sections in a $1024 \times 1024$ pixel matrix, with a spatial resolution of $12 \mu \mathrm{m}$. After selection of the regions of interest (ROI), a Gaussian filter (sigma 0.8, support 1) was used for a partial suppression of the noise. Based on histogram of attenuation distribution, tissue was segmented into woven bone (low degree of mineralization; $14.5-36 \%$ of maximal image gray value) and lamellar bone (high degree of mineralization $>36 \%$ ). Based on the described gray values, the degree of mineralization could be quantified[18].

Four regions of interest were described. The first was the total region (TOT) and was defined as the complete region between the most proximal and distal placed screws. The second, periosteal region (PER) contained the complete volume of newly formed bone tissue within the original outer cortical border of the femur. The endosteal (END), third, region contained the volume of newly formed bone within the inner cortical border (i.e. within the bone marrow cavity). The final region of interest was the actual fracture gap (GAP) itself. It was defined as the space between the 
proximal and distal fracture part with exclusion of original cortical structure and bone fragments. The regions of interest are represented schematically in figure $6 \mathrm{~A}$.

After placement of the plate-screw osteosynthesis and after euthanasia, lateral X-rays $(40 \mathrm{kV}$, 12.5 mAs, Esotron HF50, E. Schweizer AG, Switzerland) were made for evaluation of plate and screw placement and bridging of the osteotomy gap. Bridging of the gap and thus nonunion development was scored by two independent, blinded, and experienced co-workers.

\subsection{Statistical analysis}

Statistical analysis was performed using GraphPad Prism 5 (GraphPad, San Diego, California, USA). Normality was checked using the Shapiro-Wilks test. The data are represented as means and standard error of the mean (SEM). Significance was tested using ANOVA with post hoc Bonferroni correction. P-values below 0.05 were considered statistical significant. 


\section{RESULTS}

\subsection{Increased plasma amino acid concentrations in Nos3 deficient mice}

No differences were present in systemic concentrations of arginine, citrulline and ornithine between wild type mice and both nitric oxide synthase deficient groups in plasma samples obtained after 7 days of fracture healing (Figure 2A, 2B and 2C).

After 28 days of fracture healing, plasma concentrations of all amino acids were significantly enhanced in $\mathrm{Nos}^{/-}$mice compared with wild type animals (arginine: $\mathrm{p}<0.001$; Figure 2A, citrulline: $p<0.0001$; Figure 2B, ornithine: $p<0.05$; Figure $2 C)$. Arginine $(p<0.05$; Figure $2 A)$ and citrulline $(\mathrm{p}<0.0001$; Figure $2 \mathrm{~B})$ concentrations of $N o s 3^{/-}$mice also showed significant higher concentrations when compared with $\mathrm{Nos2}^{/-}$animals. Measured citrulline levels showed a distinct decrease $(p<0.01)$ in Nos2 $^{-/}$mice between samples measured at 7 and 28 days of follow-up, whereas in $\mathrm{Nos}^{-/}$animals these concentrations were enhanced $(p<0.05)$.

The arginine availability in plasma, defined by the ratio between the arginine concentration and the combined ornithine and lysine concentration decreased over time between samples obtained after 7 and 28 days of fracture healing in $\mathrm{Nos}^{-/-}$and $\mathrm{Nos}^{-/-}$animals (Figure 2D).

\subsection{Decreased amino acid concentrations in NOS2 and NOS3 deficient callus tissue}

Amino acid concentrations in femur tissue were measured in fractured bones and contralateral unfractured control bones. Arginine concentrations measured in callus tissue showed no differences between the different mouse strains at both time points (Figure $3 \mathrm{~A}$ ).

After 28 days of fracture healing, callus tissue from wild type mice showed significant higher citrulline concentrations when compared to callus tissue from 7 days of fracture healing $(p<0.05$; Figure 3B). Also, Nos2 ${ }^{-/}$mice had significantly lower citrulline concentrations compared to wild type animals at 28 days $(p<0.01)$. Callus citrulline concentrations in Nos3 ${ }^{-/-}$mice tended to be lower compared to wild type mice. 
After 28 days of fracture repair, callus tissue of wild type and $N o s 3^{-/}$mice showed $\sim 1.5-2$ fold lower ornithine concentrations when compared to callus tissue collected after 7 days $(p<0.001$ and $p<0.05$ respectively; Figure $3 C$ ).

Fractured femurs in wild type mice after 28 days showed significant lower ornithine concentrations when compared with $\operatorname{Nos}^{-/}$mice $(p<0.05)$. Fractured femurs of $\operatorname{Nos}^{-/}$as well as $\mathrm{Nos}^{-/}$mice showed significantly higher ornithine concentrations when compared with their contralateral non-fractured femurs after 7 days of fracture healing $(p<0.05$ and $p<0.01$ respectively, figure $3 \mathrm{C}$ ). The decrease of ornithine concentrations over time as visible in fractured femurs was not present in unfractured controls.

Callus tissue of wild type animals after 28 days of fracture healing showed significantly higher arginine availability (Figure 3D) when compared with both $\operatorname{Nos}^{/-}(p<0.001)$ and Nos3 ${ }^{/-}(p<$ $0.05)$ mice. The tissue arginine availability index increased between 7 and 28 days of follow-up in both wild type mice $(p<0.0001)$ and $\operatorname{Nos}^{-/-}$mice $(p<0.05)$, but not in Nos2 $2^{-/}$mice.

\subsection{Elevated myeloperoxidase influx in callus tissue of $\mathrm{Nos2}^{-/-}$and $\mathrm{Nos}^{-/-}$mice}

Femur samples of both $\mathrm{Nos2}^{-/}$and $\mathrm{Nos3}^{-/}$animals collected 28 days after the osteotomy procedure showed significantly elevated neutrophil influx $(p<0.05$ and $p<0.01$ respectively; Figure 4A and B) as measured by MPO levels in the callus region and the proximal and distal marrow cavities when compared to wild type mice. $\mathrm{Nos}^{-/-}$mice regained a normal level of MPO influx after 42 days of fracture healing, whereas $\mathrm{Nos}^{-/}$animals still showed a high degree of MPO influx ( $p<0.01$ when compared with wild type animals).

Figure $4 \mathrm{C}$ shows H\&E staining results of fractured femurs after 42 days of follow-up. Wild type animals presented with callus formation between the proximal and distal fracture parts, whereas in both $\mathrm{Nos}^{-/}$and $\mathrm{Nos}^{-/}$mice, no evident callus formation was visible.

\subsection{Upregulation of arginase-1 RNA in callus tissue}

Contralateral unfractured control femurs showed no Arginase-1 expression after both 7 and 28 days of follow-up (Figure 5A), while all fractured femurs presented detectable levels of Arginase- 
1. In addition, in all mice, Arginase-1 showed a 2-fold lower concentration at 28 days compared to 7 days. Furthermore, at 28 days Nos3 $^{-/}$mice had a significantly lower Arginase- 1 expression compared to $\mathrm{Nos}^{-/}$mice $(\mathrm{p}<0.05)$.

\subsection{Nos2 and Nos3 expression}

Nos2 mRNA expression was lower in the fractured femur at 7 days compared to the normal femur, while at 28 days the reverse was present. While Nos2 expression was absent in Nos2 ${ }^{-/}$ mice, Nos2 expression in Nos3 $^{-/}$mice was higher at 28 days (Figure 5B, $\mathrm{p}<0.05$ ).

Nos3 expression in wild type animals remained similar in fractured femur tissue at 7 and 28 days compared to non-fractured femurs. Nos3 expression at 28 days tended to be increased in Nos2 $2^{-1}$ mice compared to wild type and $\mathrm{Nos}^{-/}$mice (Figure $5 \mathrm{C}$ ).

\subsection{Evident nonunion development in $\mathrm{Nos}^{-/}$and $\mathrm{Nos}^{-/-}$on micro-computed tomography}

In figure 6B-G, qualitative images of representative micro-CT measurements are shown of femurs after 28 and 42 days of fracture repair in wild type mice, and $\mathrm{Nos2}^{-/}$and $\mathrm{Nos}^{-/}$mice. Grey structures indicate mineralized bone and green structures indicate newly formed callus tissue. Both strains of knock out mice showed almost no signs of bone formation at both time points.

Micro-CT measurements of total callus volume showed higher volumes in wild type mice when compared to both $\mathrm{Nos}^{-/}$and $\mathrm{Nos}^{-/}$animals (Figure $6 \mathrm{H}$ ) after 28 and 42 days of fracture healing $(p<0.05)$. Periosteal callus volume (Figure 6I) was significantly lower in Nos2 $2^{-1}$ mice when compared with wild types $(p<0.05)$ after 28 days of fracture healing. Endosteal callus volumes were significantly lower in $\mathrm{Nos}^{-/}$mice after 28 days of fracture healing (Figure 6J, p < 0.05). After 42 days of fracture healing, Nos2 ${ }^{--}$and $\mathrm{Nos}^{-/}$animals both showed lower periosteal and endosteal callus volumes in comparison with wild type mice $(p<0.05)$.

In the GAP region between the proximal and distal part of the femur, $\sim 3-4$ fold lower callus volumes were observed in both nitric oxide synthase deficient strains when compared to wild type mice after 28 and 42 days of fracture healing. However, due to the large variation in the quantified results, differences did not reach a level of significance (figure 6K). 
After scoring the X-rays and micro-CT images of animals euthanized after 42 days, wild type mice showed in 9 out of 9 animals bridging of the osteotomy gap. In Nos2 $2^{-/}$mice, 1 of 9 animals showed bridging, and no animals with a Nos $3^{-/}$background had sufficient callus formation. Figure 7 shows representative $\mathrm{X}$-ray images of the mice right after placement of the plate-screw osteosynthesis and after 42 days of fracture healing. 


\section{DISCUSSION}

In the present study we show that both the absence of either endothelial or inducible nitric oxide synthase results in an inadequate fracture healing, as demonstrated by the transition of a delayed union into a nonunion in mice after femur osteotomy with periosteal cauterization. Both Nos2 $2^{-/}$ and $\mathrm{Nos}^{-/}$mice also exhibited a prolonged increase of neutrophil influx in the later stages of fracture repair, indicating that a disturbed inflammatory response plays a role in the development of nonunion. Finally, deletion of the Nos2 and Nos3 gene induced a disturbed systemic and local arginine-NO metabolism.

During normal conditions, the process of bone healing in mice until there is no interfragmentary motion takes around three weeks[22]. In our study, we cauterized the periosteum to create a clinically relevant situation of compromised fracture healing. This cauterization delayed the fracture healing in wild type animals by approximately one week (data not shown).

As far as our knowledge extends, our study is the first to measure callus volume in both Nos2 and Nos3 knockout animals in comparison with wild type animals during different time points in the fracture healing process. Micro-CT is an ideal method to not only quantify tissue volumes but also to differentiate it spatially. We were able to show that $\mathrm{Nos}^{-/}$and $\mathrm{Nos}^{-/}$mice had significantly lower quantities of total callus volume, and thus the important influence of these enzymes on fracture healing. Whereas in $\mathrm{Nos}^{-/}$animals periosteal callus formation was hampered after 28 days of fracture healing, Nos3 $3^{-/}$mice showed significantly lower endosteal callus volume, suggesting different pathways in which fracture healing is disturbed in these animals.

Diwan et al and Zhu et al both showed a temporal[13] and localized[14] increased expression of NOS isoforms, compared to the normal unfractured femoral cortex[12], during the normal healing process of femoral fractures in rodents. In their studies, NOS2 was primarily present during the initial inflammatory stage and mainly found within the intramembranous region, along the edge of the periosteal callus. NOS3 is present during the secondary bone formation in cells in the chondral region and lining of blood vessels. 
In our study, a decrease in Nos2 expression in the callus tissue after 7 days of delayed fracture healing was present in wild type animals compared to normal non-fractured femurs, while the opposite occurred after 28 days. In a study by Corbett et al[23] levels of NOS2 protein displayed a similar pattern at 7 and 28 days of fracture healing. Thus, while in normal fracture healing NOS2 activity is upregulated, delayed fracture healing coincides with a decreased expression of NOS2 compared to normal bone. Indeed, with complete deletion of the NOS2 expression we demonstrate that bone healing is further compromised and nonunion occurs. This relationship is further emphasized in studies were suppression of NO synthesis by feeding rats orally with the non-selective NOS inhibitor L-nitroso-arginine methyl ester (L-NAME) resulted in a decrease of callus cross-sectional area and maximum failure load during three-point-bending tests[12]. Fractured femurs of Nos2 knockout mice are known to have a decreased maximum energy absorption and torsional failure during strength testing[24]. Biomechanical properties of unfractured Nos2 knockout femurs showed no differences when compared to those of wild type mice. These data emphasize the importance of NOS2 in fracture healing.

Our results demonstrate that in the absence of NOS3, fracture healing is hampered with decreased callus formation and nonunion development. Previously, an increased expression of NOS3 was shown in cortical blood vessels during fracture repair, which mediates an increased blood flow during normal fracture repair[23]. An experimental model of normal fracture healing in rats showed changes in local vascular reactivity at the fracture site after intravenous pharmacological stimulation or inhibition of NO during initial phases of fracture healing[6]. NOS3 is known to play a key role in postnatal regulation of bone mass, as young Nos3 knockout mice show a reduced bone volume and defects in osteoblast differentiation, maturation and activity and reduced rates of growth factors[25, 26]. These data suggest the importance of NOS3 in the later bone formation phases.

As previously reported, the inflammatory response plays an important role in normal fracture healing[1, 27]. In our study, we showed a higher level of MPO in callus tissue and proximal and distal marrow cavities in the femur of both $\mathrm{Nos}^{-{ }^{-}}$and $\mathrm{Nos}^{-/}$animals at 28 days, while it continued to be increased until 42 days in the Nos2 ${ }^{-/}$mice fracture callus. Nos2 expression is 
known to be drastically increased on RNA and protein levels in osteoblasts and bone marrow macrophages during inflammatory conditions[28]. In addition, Watanuki et al demonstrated inadequate response of bone and bone marrow cells to reloading of unloaded NOS2 deficient murine tibiae[29].

In this study, we have not looked into the role of NOS1 during the follow-up period. NOS1 is mainly up-regulated in the later stages of fracture healing[13] (i.e. bone remodeling), hence after callus formation. The fact that nonunion development depends on disturbances during the inflammatory phase and subsequent callus formation[30, 31] led us to focus on NOS2 and NOS3 which is generally expressed during the primary phases of bone healing.

In a previous study, our group already showed that disturbed amino acids concentrations were associated with nonunion development in humans[11]. In atrophic nonunions, concentrations of arginine, citrulline and ornithine were significantly lower in comparison with healthy controls. To determine the role of the substrate availability (arginine and citrulline) on delayed union and nonunion development in this model, these amino acid concentrations were measured. As observed, the arginine availability was significantly decreased after 28 days of fracture healing in Nos2 $^{-/}$and Nos3 $^{-/}$animals, which indicates the importance of NOS presence and arginine availability on fracture healing.

In this study, arginine availability was significantly decreased. Kdolsky et al were the first to report a possible influence of oral L-arginine supplementation to be beneficial on fracture healing in an in vivo study in guinea pigs[32] with signs of improved fracture healing on radiographic imaging. Based on these findings and this study, we hypothesize that stimulation of the arginine-NO metabolism might be a promising possible therapeutic option in decreasing the percentage of nonunion and delayed union development after fractures. Further research into amino acids associated with the arginine-NO metabolism is needed to elucidate these possibilities in bone anabolism and catabolism. In muscle tissue it is known that in patients who are immobilized due to long term hospital admission and immobility, anabolic reactions in muscles are diminished whereas catabolism is enhanced. 
In conclusion, this study shows that a disturbed arginine-NO metabolism by blocking inducible or endothelial NOS facilitates the development of nonunion in a delayed union mouse model. 


\section{DISCLOSURES}

All authors declare no conflict of interest.

\section{AUTHOR'S CONTRIBUTIONS}

Study design: SZ, KI, PB, MP. Animal experiments: SZ, SN. Acquisition of data: DM, FH. Data analysis: DM, KW, FH, SZ, MP. Study oversight: MP, SZ. Drafting and revising manuscript: DM. Reviewing manuscript: KW, FH, SZ, KI, PB, MP.

\section{ACKNOWLEDGEMENTS}

The authors would like to thank Mr. C. Boymans for his skilled assistance during the preparation of tissue samples, Ms. L. Kusters for her work during RNA isolation and subsequent PCRs and Dr. H.M.H. van Eijk for performing the amino acid measurements. 


\section{REFERENCES}

[1] Schindeler A, McDonald MM, Bokko P, Little DG. Bone remodeling during fracture repair: The cellular picture. Semin Cell Dev Biol 2008;19: 459-66.

[2] Mills LA, Simpson AH. The relative incidence of fracture non-union in the Scottish population (5.17 million): a 5-year epidemiological study. BMJ Open 2013;3.

[3] Brighton CT, Shaman P, Heppenstall RB, Esterhai JL, Jr., Pollack SR, Friedenberg ZB. Tibial nonunion treated with direct current, capacitive coupling, or bone graft. Clin Orthop Relat Res 1995: 223-34.

[4] Jahagirdar R, Scammell BE. Principles of fracture healing and disorders of bone union. Surgery 2009;27: 63-69.

[5] Frolke JP, Patka P. Definition and classification of fracture non-unions. Injury 2007;38 Suppl 2: S19-22.

[6] Corbett SA, McCarthy ID, Batten J, Hukkanen M, Polak JM, Hughes SP. Nitric oxide mediated vasoreactivity during fracture repair. Clin Orthop Relat Res 1999: 247-53.

[7] Chae HJ, Park RK, Chung HT, Kang JS, Kim MS, Choi DY, Bang BG, Kim HR. Nitric oxide is a regulator of bone remodelling. $\mathrm{J}$ Pharm Pharmacol 1997;49: 897-902.

[8] Baldik Y, Talu U, Altinel L, Bilge H, Demiryont M, Aykac-Toker G. Bone healing regulated by nitric oxide: an experimental study in rats. Clin Orthop Relat Res 2002: 343-52.

[9] Vittur F, Lunazzi G, Moro L, Stagni N, de Bernard B, Moretti M, Stanta G, Bacciottini F, Orlandini $\mathrm{G}$, Reali N, et al. A possible role for polyamines in cartilage in the mechanism of calcification. Biochim Biophys Acta 1986;881: 38-45.

[10] Xia W, Szomor Z, Wang Y, Murrell GA. Nitric oxide enhances collagen synthesis in cultured human tendon cells. J Orthop Res 2006;24: 159-72.

[11] Wijnands KA, Brink PR, Weijers PH, Dejong $\mathrm{CH}$, Poeze M. Impaired fracture healing associated with amino acid disturbances. Am J Clin Nutr 2012;95: 1270-7.

[12] Diwan $A D$, Wang $M X$, Jang $D$, Zhu W, Murrell GA. Nitric oxide modulates fracture healing. J Bone Miner Res 2000;15: 342-51.

[13] Zhu W, Diwan AD, Lin JH, Murrell GA. Nitric oxide synthase isoforms during fracture healing. J Bone Miner Res 2001;16: 535-40.

[14] Zhu W, Murrell GA, Lin J, Gardiner EM, Diwan AD. Localization of nitric oxide synthases during fracture healing. J Bone Miner Res 2002;17: 1470-7.

[15] Laubach VE, Shesely EG, Smithies O, Sherman PA. Mice lacking inducible nitric oxide synthase are not resistant to lipopolysaccharide-induced death. Proc Natl Acad Sci U S A 1995;92: 10688-92.

[16] Shesely EG, Maeda N, Kim HS, Desai KM, Krege JH, Laubach VE, Sherman PA, Sessa WC, Smithies O. Elevated blood pressures in mice lacking endothelial nitric oxide synthase. Proc Natl Acad Sci U S A 1996;93: 13176-81.

[17] Matthys R, Perren SM. Internal fixator for use in the mouse. Injury 2009;40 Suppl 4: S103-9.

[18] Grongroft I, Heil P, Matthys R, Lezuo P, Tami A, Perren S, Montavon P, Ito K. Fixation compliance in a mouse osteotomy model induces two different processes of bone healing but does not lead to delayed union. J Biomech 2009;42: 2089-96.

[19] van Eijk HM, Rooyakkers DR, Deutz NE. Rapid routine determination of amino acids in plasma by high-performance liquid chromatography with a 2-3 microns Spherisorb ODS II column. J Chromatogr 1993;620: 143-8.

[20] Morris CR, Poljakovic M, Lavrisha L, Machado L, Kuypers FA, Morris SM, Jr. Decreased arginine bioavailability and increased serum arginase activity in asthma. Am J Respir Crit Care Med 2004;170: 148-53.

[21] Hong SK, Maltz BE, Coburn LA, Slaughter JC, Chaturvedi R, Schwartz DA, Wilson KT. Increased serum levels of L-arginine in ulcerative colitis and correlation with disease severity. Inflamm Bowel Dis 2010;16: 105-11.

[22] Garcia $\mathrm{P}$, Histing $\mathrm{T}$, Holstein $\mathrm{JH}$, Klein $\mathrm{M}$, Laschke $\mathrm{MW}$, Matthys $\mathrm{R}$, Ignatius $\mathrm{A}$, Wildemann B, Lienau J, Peters A, Willie B, Duda G, Claes L, Pohlemann T, Menger MD. Rodent 
animal models of delayed bone healing and non-union formation: a comprehensive review. Eur Cell Mater 2013;26: 1-12; discussion 12-4.

[23] Corbett SA, Hukkanen M, Batten J, McCarthy ID, Polak JM, Hughes SP. Nitric oxide in fracture repair. Differential localisation, expression and activity of nitric oxide synthases. J Bone Joint Surg Br 1999;81: 531-7.

[24] Baldik Y, Diwan AD, Appleyard RC, Fang ZM, Wang Y, Murrell GA. Deletion of iNOS gene impairs mouse fracture healing. Bone 2005;37: 32-6.

[25] Aguirre J, Buttery L, O'Shaughnessy M, Afzal F, Fernandez de Marticorena I, Hukkanen $M$, Huang $P$, Maclntyre I, Polak J. Endothelial nitric oxide synthase gene-deficient mice demonstrate marked retardation in postnatal bone formation, reduced bone volume, and defects in osteoblast maturation and activity. Am J Pathol 2001;158: 247-57.

[26] Armour KE, Armour KJ, Gallagher ME, Godecke A, Helfrich MH, Reid DM, Ralston SH. Defective bone formation and anabolic response to exogenous estrogen in mice with targeted disruption of endothelial nitric oxide synthase. Endocrinology 2001;142: 760-6.

[27] Claes L, Recknagel S, Ignatius A. Fracture healing under healthy and inflammatory conditions. Nat Rev Rheumatol 2012;8: 133-43.

[28] Helfrich MH, Evans DE, Grabowski PS, Pollock JS, Ohshima H, Ralston SH. Expression of nitric oxide synthase isoforms in bone and bone cell cultures. J Bone Miner Res 1997;12: 1108-15.

[29] Watanuki M, Sakai A, Sakata T, Tsurukami H, Miwa M, Uchida Y, Watanabe K, Ikeda K, Nakamura T. Role of inducible nitric oxide synthase in skeletal adaptation to acute increases in mechanical loading. J Bone Miner Res 2002;17: 1015-25.

[30] Bastian O, Pillay J, Alblas J, Leenen L, Koenderman L, Blokhuis T. Systemic inflammation and fracture healing. J Leukoc Biol 2011;89: 669-73.

[31] Reikeras O, Shegarfi H, Wang JE, Utvag SE. Lipopolysaccharide impairs fracture healing: an experimental study in rats. Acta Orthop 2005;76: 749-53.

[32] Kdolsky RK, Mohr W, Savidis-Dacho H, Beer R, Puig S, Reinsner R, Tangl S, Donath K. The influence of oral L-arginine on fracture healing: an animal study. Wien Klin Wochenschr 2005;117: 693-701. 


\section{COLLAGEN SYNTHESIS}

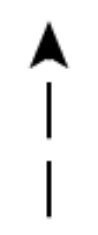

\section{ORNITHINE}
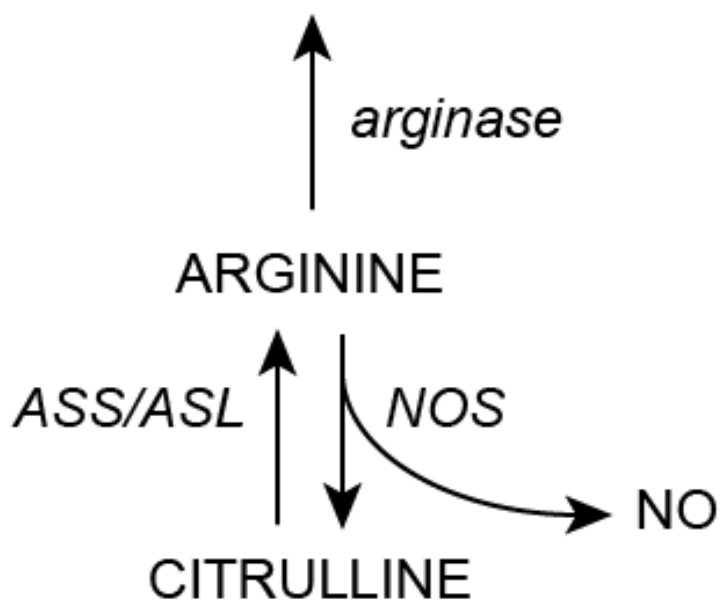

\section{FIGURE 1}

Schematic representation of arginine metabolism. Arginine can be converted into ornithine by the enzyme arginase. Ornithine is a precursor of collagen. Arginine can also be converted into citrulline by one of the nitric oxide synthases (NOS); neuronal NOS1, inducible NOS2 or endothelial NOS3. During this process the free radical nitric oxide (NO) is produced. Citrulline can be converted back into arginine by the enzymes ASS (argininosuccinate synthase) and ASL (argininosuccinate lyase). 
A

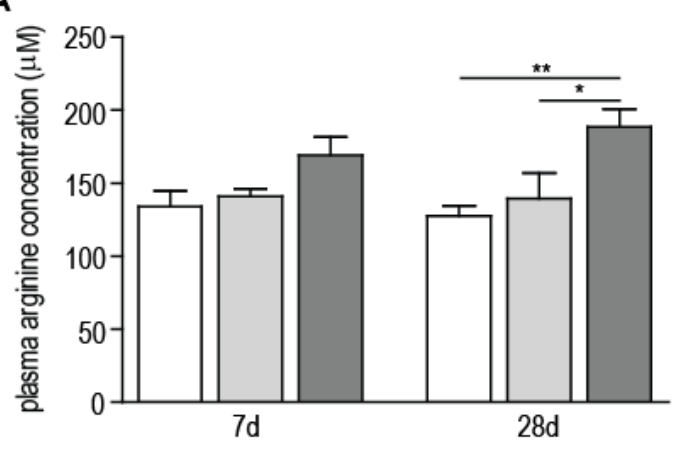

。

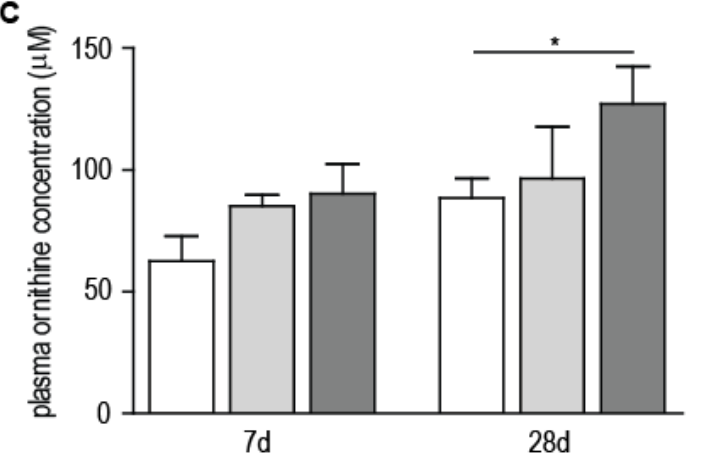

B

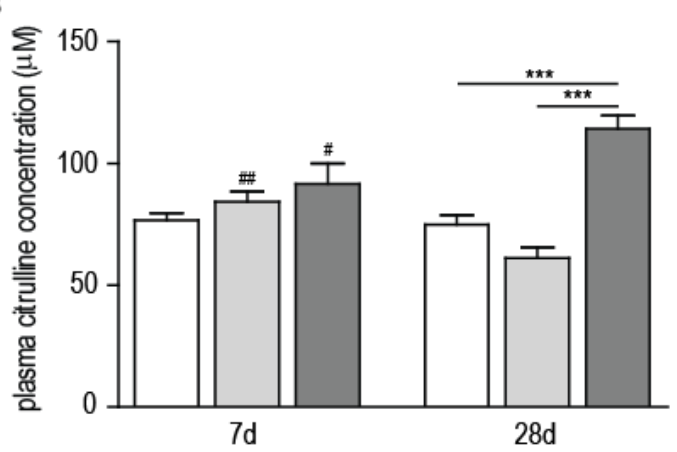

D

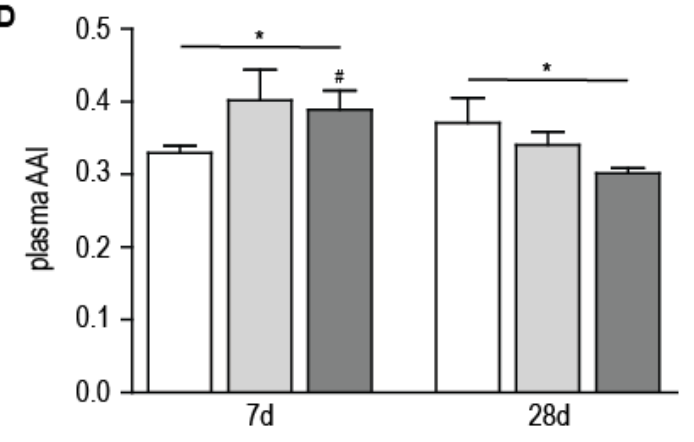

\section{FIGURE 2}

Plasma concentrations $(\mu \mathrm{M})$ of arginine $(\mathrm{A})$, citrulline $(\mathrm{B})$ and ornithine $(\mathrm{C})$ in mice after 7 and 28

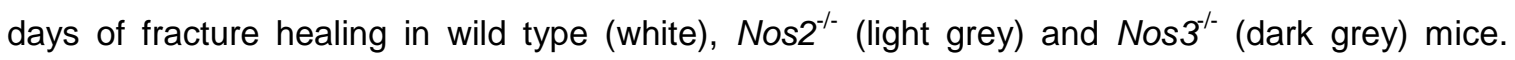
Plasma arginine availability index (AAI, D) was calculated as the ratio between the arginine concentration and combined ornithine and lysine concentrations. Significance levels between mouse strains: ${ }^{*}: p<0.05 ;^{* *}: p<0.001{ }^{* * *}: p<0.0001$. Significance levels between time points: $\#: p<0.05 ; \#: p<0.01$. 

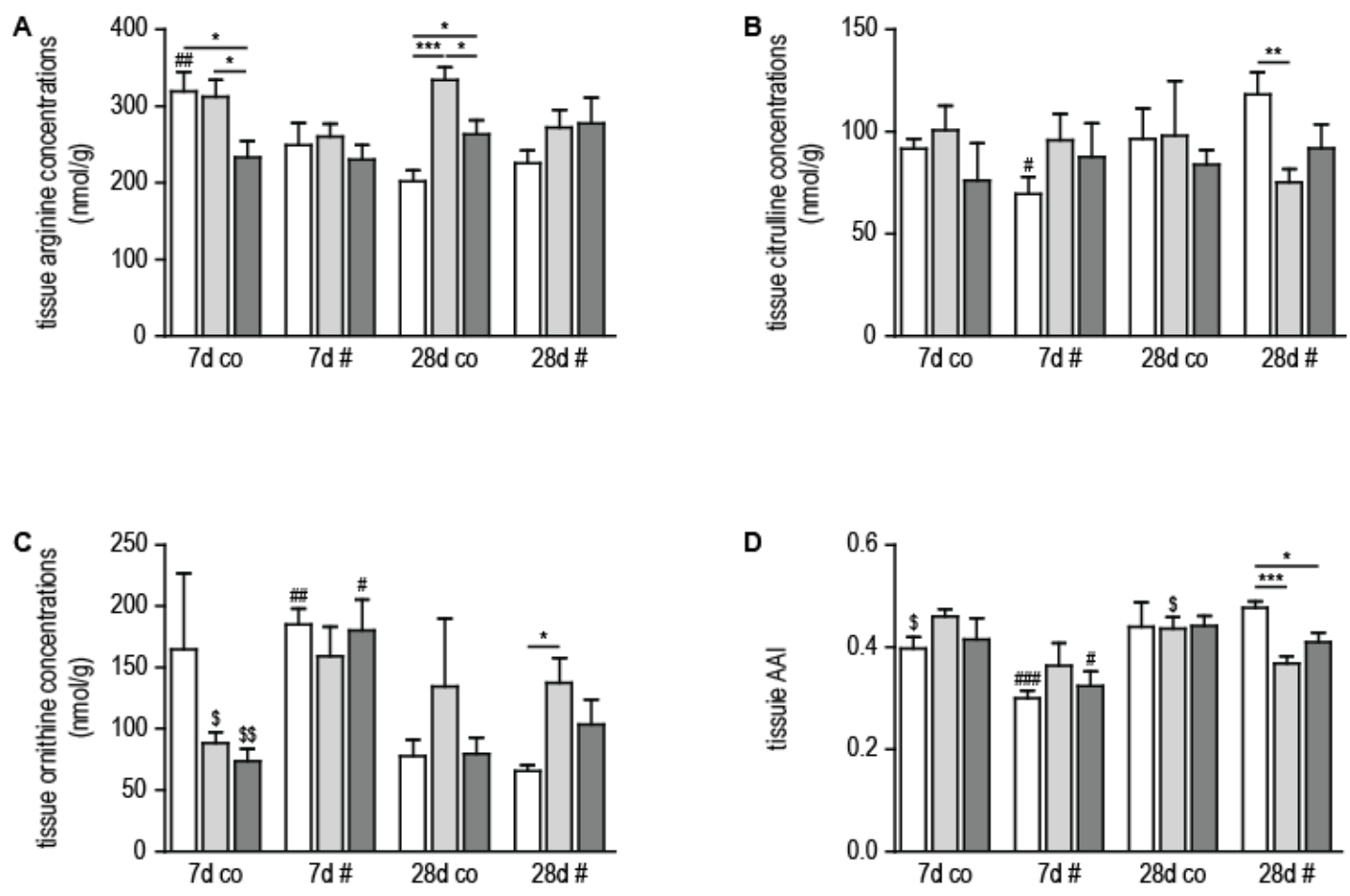

$\square$ WT $\square$ Nos2 $^{-\alpha} \square$ Nos3 $^{+}$

\section{FIGURE 3}

Arginine (A), citrulline (B) and ornithine (C) concentrations in femoral callus tissue in $\mathrm{nmol} / \mathrm{g}$, measured after 7 and 28 days of fracture healing in osteotomized (\#) and contralateral

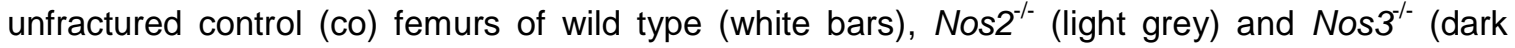
grey) mice. Arginine availability index (AAI, D) was calculated as the ratio between the arginine concentration and combined ornithine and lysine concentrations. Significance levels between mouse strains: ${ }^{*}: p<0.05 ;{ }^{* *}: p<0.01 ;^{* * *}: p<0.001$. Significance levels between time points: \#: $p<0.05 ; \# \#: p<0.01 ; \# \#: p<0.0001$. Significance between control and fractured femurs: $\$: p<$ 0.05 and $\$ \$: p<0.01$. 

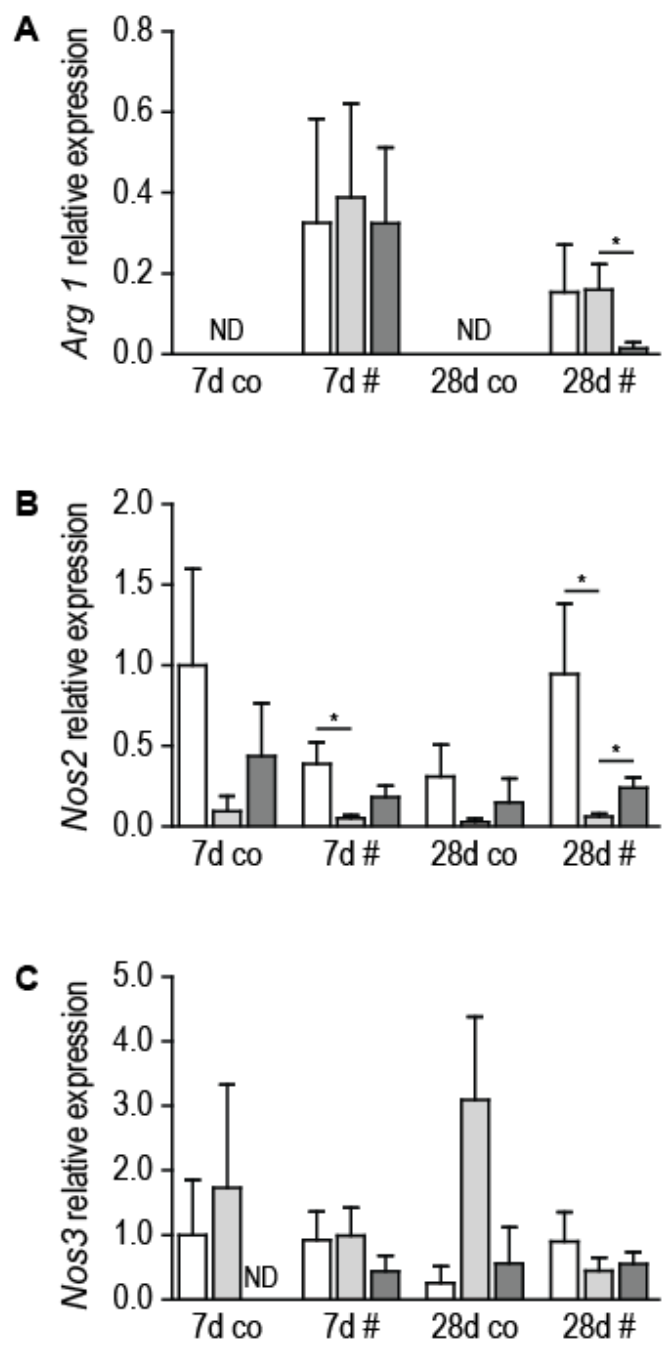

$\square$ WT $\square$ Nos2 $^{+-} \square$ Nos3 $^{+-}$

\section{FIGURE 4}

Relative RNA expression of Arginase-1 (Arg-1, A), inducible nitric oxide synthase (Nos2, B) and endothelial nitric oxide synthase (Nos3, C) measured in femoral callus tissue after 7 and 28 days of fracture healing in osteotomized (\#) and contralateral unfractured control (co) femurs of wild type (white bars), Nos2 ${ }^{--}$(light grey) and $\operatorname{Nos}^{-/-}$(dark grey) mice. * $\mathrm{p}<0.05$. ND: not detectable. 


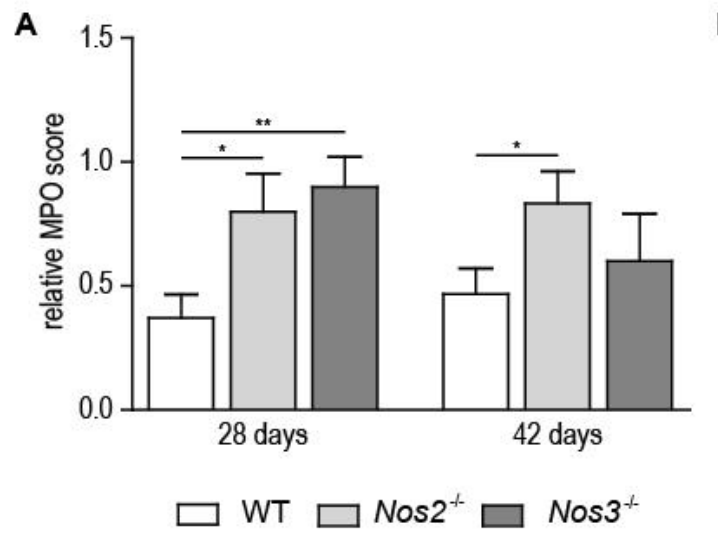

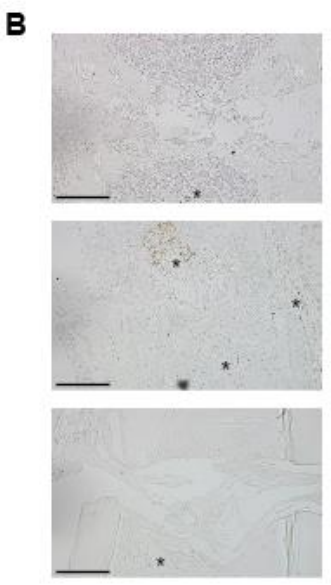

28 days
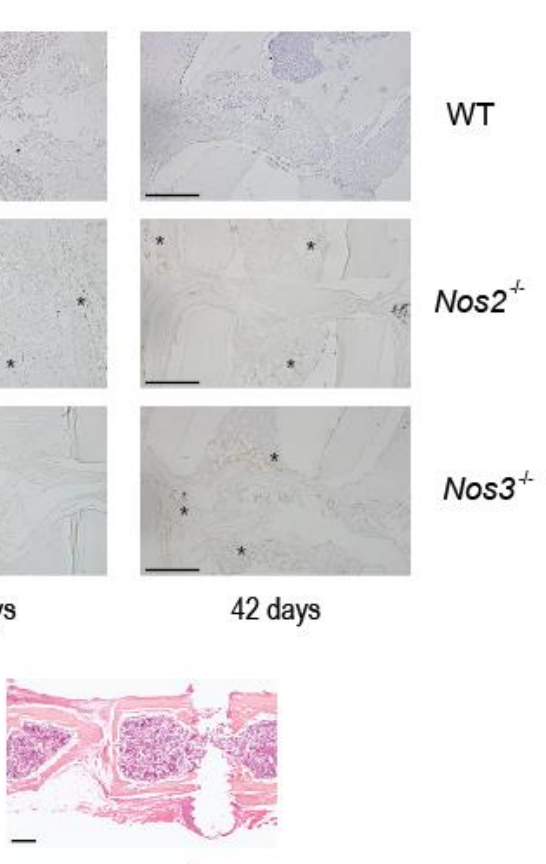

$\operatorname{Nos} 3^{1-}$

\section{FIGURE 5}

Relative myeloperoxidase (MPO) score as scored by 2 independent blinded researchers on 3 anatomical locations (proximal and distal marrow cavity and callus) in murine femurs at 28 and 42

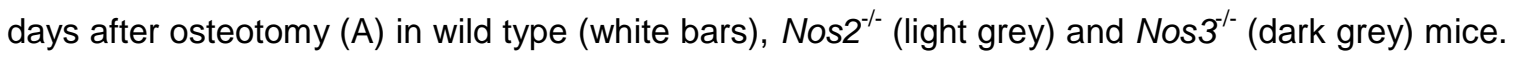
${ }^{*}: p<0.05 ;{ }^{* *}: p<0.01$. Panel B shows representative qualitative MPO stainings of each group. Asterixes in (B) indicate MPO staining. (C) shows H\&E staining of fractured femurs after 42 days of fracture healing of wild type and both NOS deficient groups of animals. Scale bars in (B) and (C) represent a range of $0.5 \mathrm{~mm}$. 
A
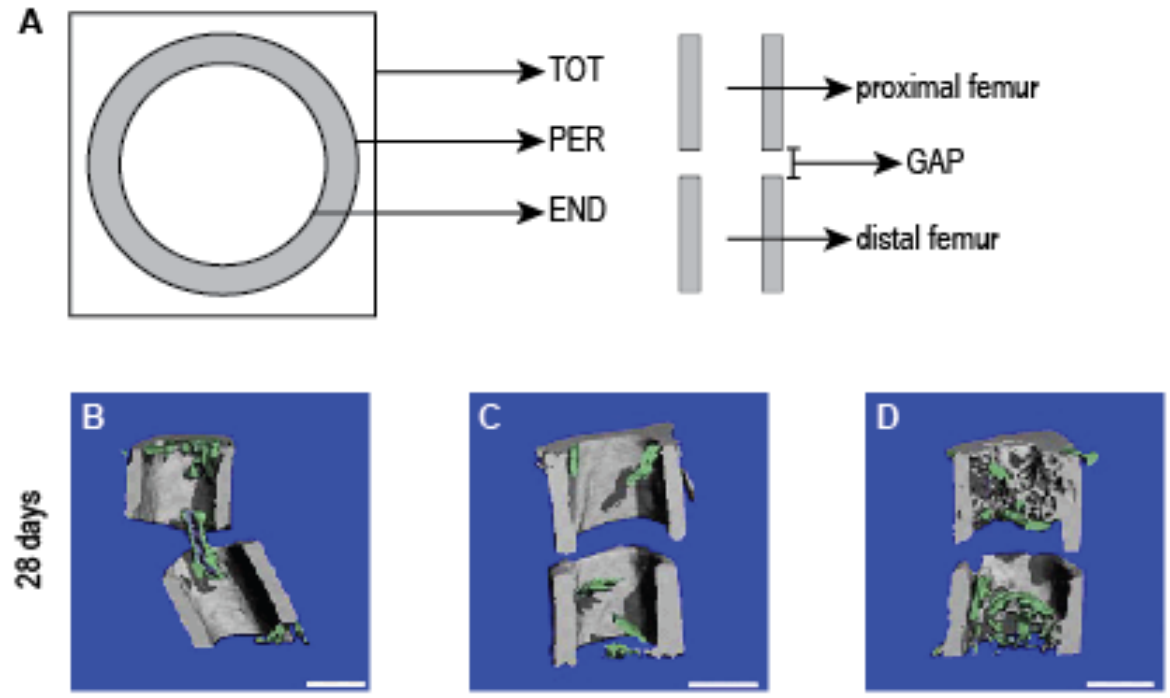

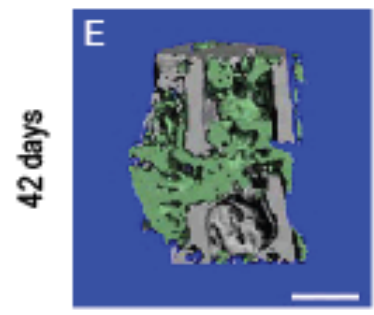

wild type

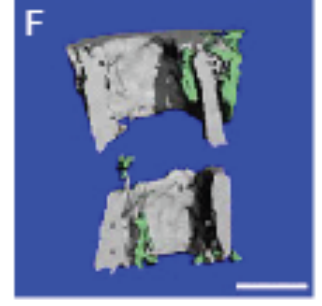

Nos2 KO

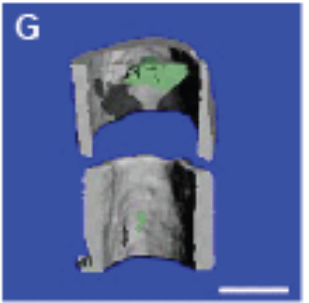

Nos3 KO
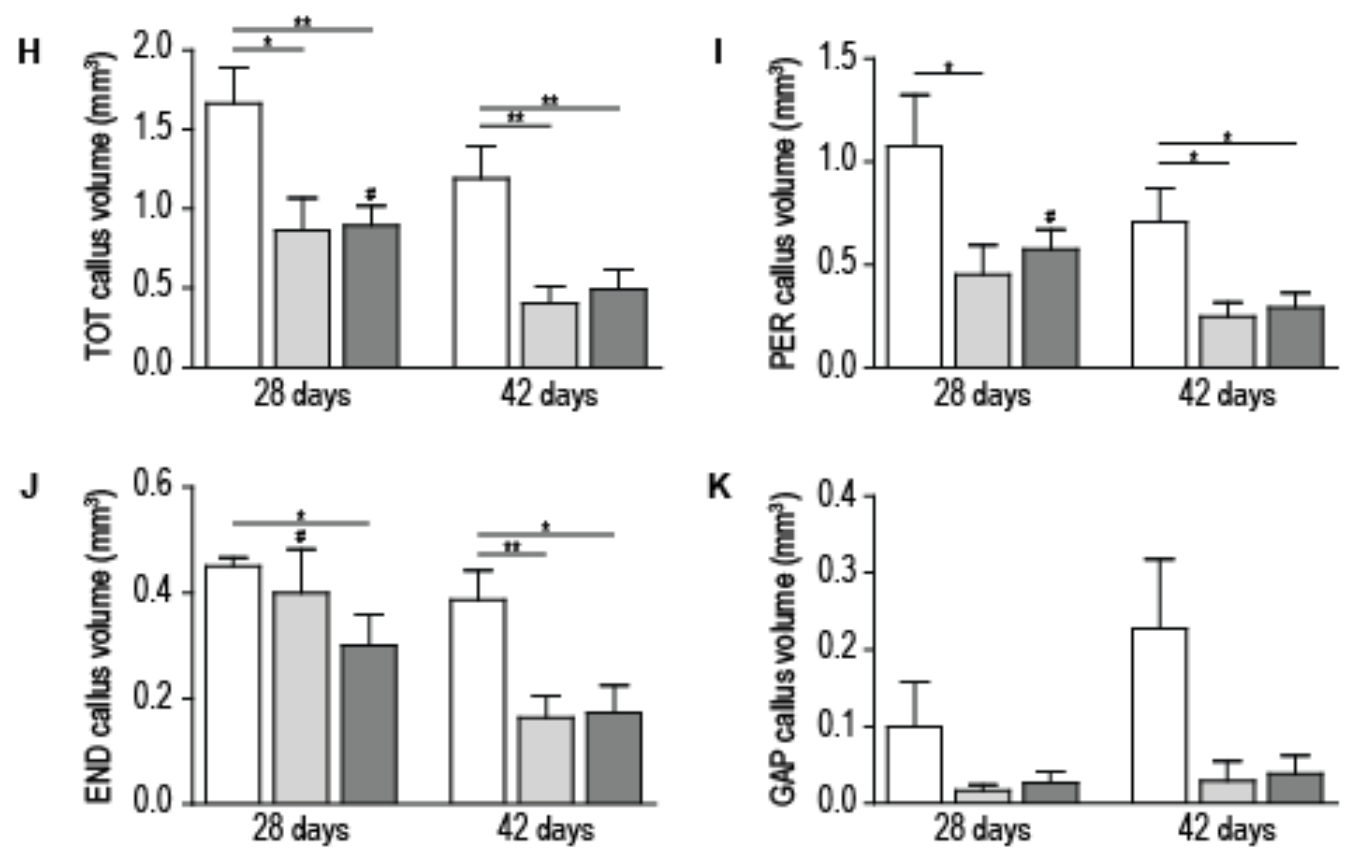

$\square$ WT $\square$ Nos $2^{*} \square \operatorname{Nos} 3^{*}$ 


\section{FIGURE 6}

(A) shows a schematic representation of the four different regions of interest measured with $\mu \mathrm{CT}$ :

TOT: Total region between de most proximal and distal screw, PER: periosteal region, END: endosteal region and GAP: the part between the proximal and distal part of the femur where the osteotomy was performed. (B) to $(G)$ show qualitative images of the different groups. (B): wild

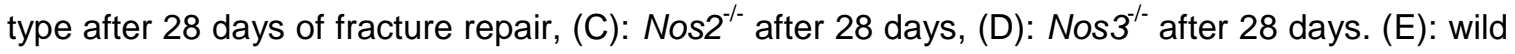
type after 42 days, (F): Nos2 ${ }^{/-}$after 42 days and (G): Nos3 ${ }^{--}$after 42 days. Grey structures indicate bone tissue, green represents developed callus tissue. Scale bars indicate a length of 1 $\mathrm{mm}$.

Callus volume (in $\mathrm{mm}^{3}$ ) after $\mu \mathrm{CT}$ measurement of four different regions of interest: $(\mathrm{H})$ : TOT, (I): PER, (J): END and (K): GAP. White bars represent wild type mice, light grey Nos2 ${ }^{-/}$and dark grey Nos3 ${ }^{-{ }^{*}}$. $: p<0.05$ (difference between mouse strains), ${ }^{* *}: p<0.01 ; \#: p<0.05$ (difference between time points). 

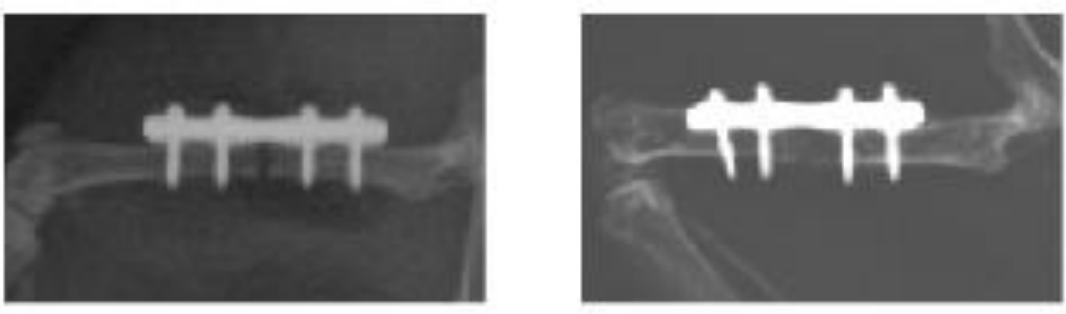

WT
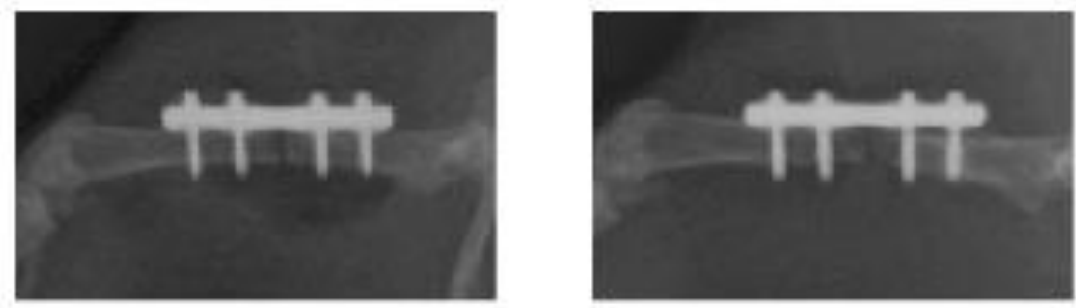

Nos2 $2^{+}$
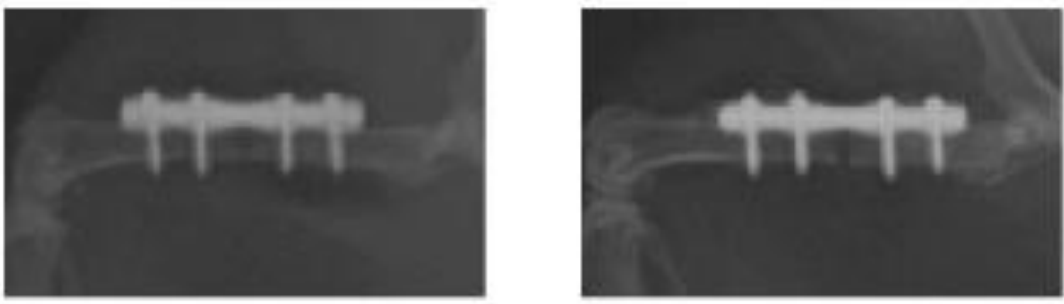

Nos3*

Post-operative

42 days

\section{FIGURE 7}

Radiologic X-ray analysis of wild type, $\mathrm{Nos}^{-/}$and $\mathrm{Nos}^{-/}$mice after placement of the plate-screw osteosynthesis to assess correct placement and at 42 days of fracture healing. 


\section{TABLE 1}

Number of animals per mouse strain, days of follow-up and type of analysis.

\begin{tabular}{l|l|lll} 
Analysis & Days & Wild type & Nos2 $^{-/-}$ & Nos3 $^{-/-}$ \\
\hline Micro-CT & 28 & 8 & 9 & 9 \\
& 42 & 9 & 9 & 9 \\
\hline RNA and & 7 & 6 & 6 & 6 \\
amino & 28 & 6 & 5 & 6 \\
acids & & & 9 & 9 \\
\hline Histology & 28 & 8 & 9 & 9
\end{tabular}




\section{TABLE 2}

Primer sequences for quantitative PCR

\begin{tabular}{l|ll} 
Gene & Name & Primer sequence $\left(\mathbf{5}^{\prime} \rightarrow \mathbf{3}^{\prime}\right)$ \\
\hline Arg1 & Arg1-F & GGAGAGCCTTCCTGCACTTT \\
& Arg1-R & GTGCCTTGGTCTACATTGAACATAC \\
\hline Nos2 & iNOS-F & TTGCAAGCTGATGGTCAAGATC \\
& iNOS-R & CAACCCGAGCTCCTGGAA \\
\hline Nos3 & eNOS-F & TTAATGTGGCCGTGTTGCA \\
& eNOS-R & CTCTTGATGGAAGACAGGAGTTAGG \\
\hline ActB & B-actin-F & GACAGGATGCAGAAGGAGATTACTG \\
& B -actin-R & CCACCGATCCACACAGAGTACTT \\
\hline Ppia & CycloA-F & TTCCTCCTTTCACAGAATTATTCCA \\
& CycloA-R & CCGCCAGTGCCATTATGG
\end{tabular}

Abbreviations: F: forward primer; R: reversed primer 